\title{
X-ray Spectroscopic Study of Solvent Effects on the Ferrous and Ferric Hexacyanide Anions
}

\author{
T. J. Penfold, ${ }^{\dagger}$ M. Reinhard, ${ }^{\ddagger}$ M. H. Rittmann-Frank, ${ }^{\ddagger}$ I. Tavernelli, $^{\text {II }}$ U. Rothlisberger, ${ }^{\text {II }}$ C. J. Milne, ${ }^{\dagger}$ \\ P. Glatzel, ${ }^{\S}$ and M. Chergui ${ }^{*}$, \\ ${ }^{\dagger}$ SwissFEL, Paul Scherrer Institute, CH-5232 Villigen, Switzerland \\ ${ }^{\ddagger}$ Laboratoire de spectroscopie ultrarapide and ${ }^{\text {TI }}$ Laboratoire de chimie et biochimie computationnelles, ISIC, FSB-BSP, École \\ Polytechnique Fédérale de Lausanne (EPFL), CH-1015 Lausanne, Switzerland \\ ${ }^{\S}$ European Synchrotron Radiation Facility, Boîte Postale 220, 38043 Grenoble Cedex 9, France
}

\section{Supporting Information}

ABSTRACT: We present an Fe K $\alpha$ resonant inelastic X-ray scattering (RIXS) and X-ray emission (XES) study of ferrous and ferric hexacyanide dissolved in water and ethylene glycol. We observe that transitions below the absorption edge show that the solvent has a distinct effect on the valence electronic structure. In addition, both the RIXS and XES spectra show a stabilization of the $2 p$ levels when dissolved in water. Using molecular dynamics simulations, we propose that this effect arises from the hydrogen-bonding interactions between the complex and nearby solvent molecules. This withdraws electron density from the ligands, stabilizing the complex but also causing a slight increase in $\pi$ backbonding.

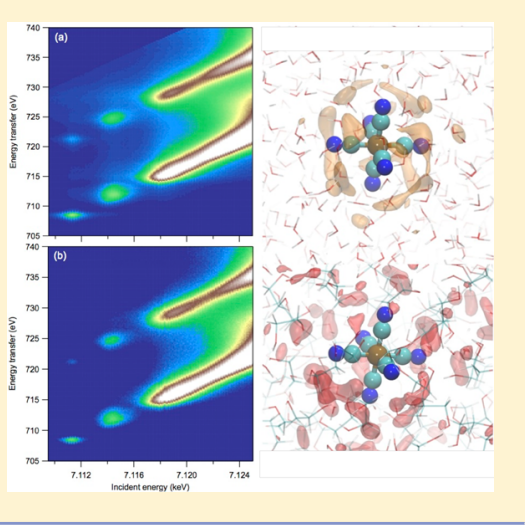

\section{INTRODUCTION}

The ability of a wide variety of transition-metal complexes to promote complicated chemical and photophysical processes makes the understanding of their properties of fundamental as well as practical importance. Of particular interest is describing the nature of the bond between the transition metal and its ligands, which often has a significant role in determining many of the properties crucial to the function of metalloproteins, catalysts, and light-harvesting molecules. ${ }^{1-6}$ In the case of $\pi$ conjugated ligands, these bonds are usually cast in terms of the interaction between unoccupied metal orbitals and occupied ligand orbitals, called $\sigma$-donation, and the mixing between the occupied metal orbitals and the unoccupied ligand orbitals, called $\pi$-backbonding. ${ }^{7-9}$ The stability and reactivity of these complexes is often strongly dependent on the relative contribution of these effects, and therefore, describing them is important in order to engineer their properties for possible applications.

Owing to their direct atomic sensitivity, X-ray spectroscopies have emerged as an important tool for studying these effects. Kedge spectroscopy of the metal (excitation of 1s core electrons) can be used to probe its oxidation state and the structure of the surrounding ligands. While additional information about the valence metal $\mathrm{d}$ orbitals can be extracted through the pre-edge region, ${ }^{10}$ these transitions are usually weak owing to the quadrupole transition moment. Consequently, complementary to this are the $L_{2 / 3}$-edges $(2 p \rightarrow 3 d),{ }^{11}$ which by virtue of the dipole selection rules are able to directly probe the metal $d$ orbitals or, more specifically for description of $\sigma$-donation and $\pi$-backbonding effects, their distribution throughout the valence space as evidenced by the line widths and line shapes.

The ferrous and ferricyanide anions $\left(\left[\mathrm{Fe}(\mathrm{CN})_{6}\right]^{4-}\right.$ and $\left[\mathrm{Fe}(\mathrm{CN})_{6}\right]^{3-}$, respectively) have been widely studied as model systems for understanding the $\sigma$-donation and $\pi$-backbonding interactions within transition-metal complexes. Using $\mathrm{Fe}_{2 / 3^{-}}$ edge XAS of both anions, Hocking et al. ${ }^{12}$ showed that $\mathrm{CN}^{-}$ back bonds slightly more to $\mathrm{Fe}^{2+}$ than to $\mathrm{Fe}^{3+}$ and acts as a strong donor to $\mathrm{Fe}^{3+}$. These conclusions are in agreement with Vinogradov et al., ${ }^{13,14}$ who used both the $\mathrm{N} \mathrm{K}$ - and metal $\mathrm{L}_{2,3^{-}}$ edges to study a range of metal cyanides. Importantly, the overall structural changes between the two complexes is very small $^{15-17}$ because $\pi$-backbonding and $\sigma$-donation have opposite effects on bonding strengths. Recently, Lundberg et al. ${ }^{18}$ used K $\alpha$ RIXS to obtain a more detailed insight into the covalency of metal-ligand bonds. They demonstrated that the two-photon process of RIXS reaches final states with the same symmetry as that in the previous study at the $\mathrm{Fe}_{2 / 3}$-edge ${ }^{12}$ but that the information content was enhanced as both the absorbed and emitted photons are resolved.

Importantly, these previous experiments have all been performed on solid samples and therefore were unable to shed light upon the role of the interaction between the solvent

Received: June 5, 2014

Revised: September 1, 2014

Published: September 15, 2014 

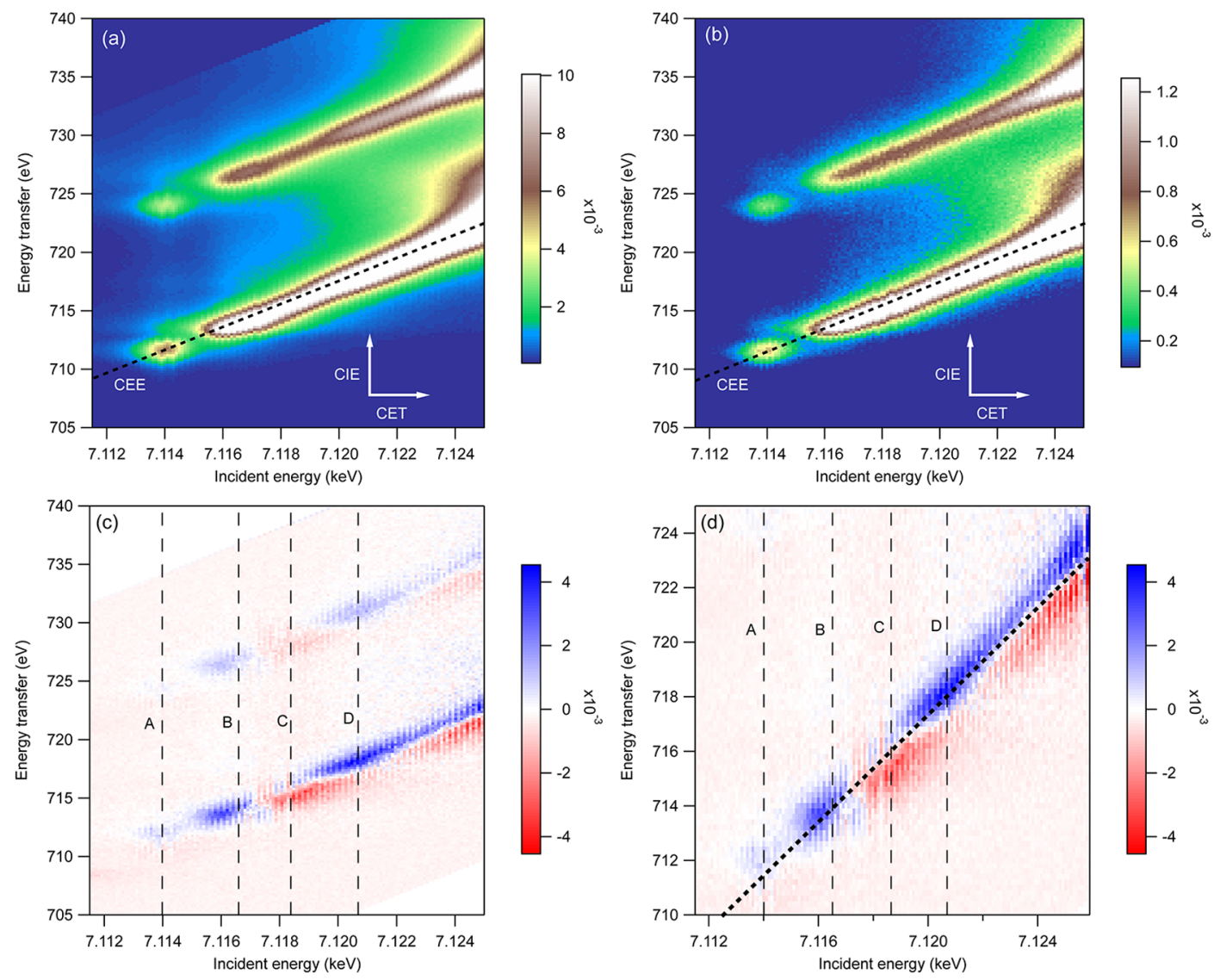

Figure 1. RIXS planes of $\left[\mathrm{Fe}(\mathrm{CN})_{6}\right]^{4-}$ in water $(\mathrm{a})$ and ethylene glycol $(\mathrm{b})$. The difference spectrum $\left[\mathrm{Fe}(\mathrm{CN})_{6}\right]^{4-}($ water $)-\left[\mathrm{Fe}(\mathrm{CN})_{6}\right]^{4-}$ (ethylene glycol), after the latter has been scaled by a factor of 8 to account for the different concentrations, is shown in (c). (d) A zoom of the difference spectrum on the $\mathrm{K} \alpha_{1}$ emission line. CIE is the constant incident energy axis, and CET is the constant energy transfer axis. CEE is the constant emission energy axis.

and the solute, ${ }^{19}$ critical to many chemical reactions that occur in the solution phase. Metal cyanides are known to be very sensitive to changes in the environment, ${ }^{20-22}$ and in particular, for $\left[\mathrm{Fe}(\mathrm{CN})_{6}\right]^{4-}$ and $\left[\mathrm{Fe}(\mathrm{CN})_{6}\right]^{3-}$, previous experiments ${ }^{23,24}$ have highlighted a strong excitation wavelength dependence of their photochemistry that leads to at least two distinct product channels, namely, the photo-oxidative and photoaquated products. ${ }^{25}$ It remains unclear what the exact mechanism is behind these processes, and a solvent effect is not to be ruled out. This could be by simply altering the relative energies of the product states, modulating the dissipation of energy from the solute to the solvent, or be more involved such as the solvent molecules explicitly taking part in the chemical reaction arising from a pre-existing electronic interaction between the solute and the solvent.

In this contribution, we present an Fe K $\alpha$ RIXS and XES study of $\left[\mathrm{Fe}(\mathrm{CN})_{6}\right]^{4-}$ and $\left[\mathrm{Fe}(\mathrm{CN})_{6}\right]^{3-}$ dissolved in water and ethylene glycol. The above ionization resonances of the Fe Kedge high-energy resolution fluorescence detected (HERFD) spectrum $^{26,27}$ extracted from the RIXS planes are solventindependent. However, for both complexes, the pre-edge regions exhibit a clear solvent effect. With the help of quantum mechanics/molecular mechanics (QM/MM) molecular dynamics (MD) simulations, ${ }^{28-30}$ we propose that this arises from hydrogen bonding between the solute and solvent, which withdraws $\pi$-electron density from the $\mathrm{CN}^{-}$. This helps in stabilizing the large negative charge on the complex and also causes a slight increase in $\pi$-backbonding.

\section{RESULTS}

In the following sections, we present the K $\alpha$ RIXS and XES spectra of $\left[\mathrm{Fe}(\mathrm{CN})_{6}\right]^{4-}$ and $\left[\mathrm{Fe}(\mathrm{CN})_{6}\right]^{3-}$ dissolved in water and ethylene glycol. These were carried out at the ID26 beamline of the European Synchrotron Radiation Facility (ESRF) in Grenoble, France. Details concerning the setup can be found in ref 26 and are also given, with the computational details, in the Supporting Information (SI).

Ferrous Hexacyanide. Figure $1 \mathrm{a}$ and $\mathrm{b}$ shows the K $\alpha$ RIXS planes of $\left[\mathrm{Fe}(\mathrm{CN})_{6}\right]^{4-}$ dissolved in water and ethylene glycol, respectively. Both spectra exhibit two principal diagonal planes that correspond to the $K \alpha_{1}$ and $K \alpha_{2}$ emission lines, split by $2 p$ core hole spin-orbit coupling. A pre-edge feature at $\Omega$ (incident energy) $=7.114 \mathrm{keV}$ is also present in both spectra and has been assigned to the $1 \mathrm{~s} \rightarrow 3 \mathrm{~d}\left(\mathrm{e}_{\mathrm{g}}\right)$ quadrupole transition. ${ }^{31}$ Due to the strong ligand field effect of the $\mathrm{CN}^{-}$, this appears in close proximity to the rising edge. ${ }^{18}$

Figure 1c shows the difference between the RIXS planes for $\left[\mathrm{Fe}(\mathrm{CN})_{6}\right]^{4-}$ in water and ethylene glycol, once the latter has been scaled to take into account the different concentrations $(\times 8)$. Figure $1 \mathrm{~d}$ shows a zoom into the $\mathrm{K} \alpha_{1}$ emission. The main changes correspond to a shift along the constant energy emission (CEE) axis (diagonal line shown in Figure 1d) and along the energy transfer axis. This latter change shows that the emission from the complex dissolved in water occurs at high energy transfer (i.e., lower emission energies), indicating that the $2 p_{1 / 2}$ and $2 p_{3 / 2}$ levels are stabilized for the complex in water. This observation is supported by the nonresonant $\mathrm{K} \alpha$ 

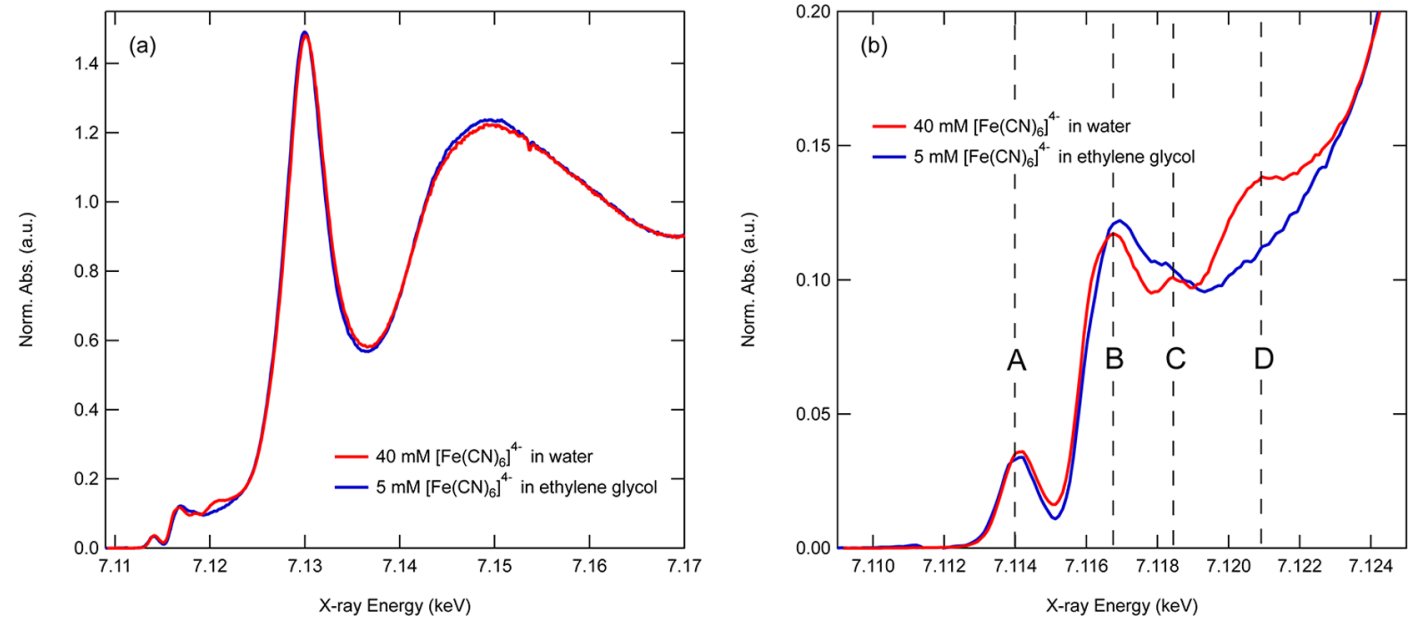

Figure 2. (a) K $\alpha$ HERFD spectra of $\left[\mathrm{Fe}(\mathrm{CN})_{6}\right]^{4-}$ dissolved in water (red) and ethylene glycol (blue). (b) A zoom of the pre-edge region of the two spectra.
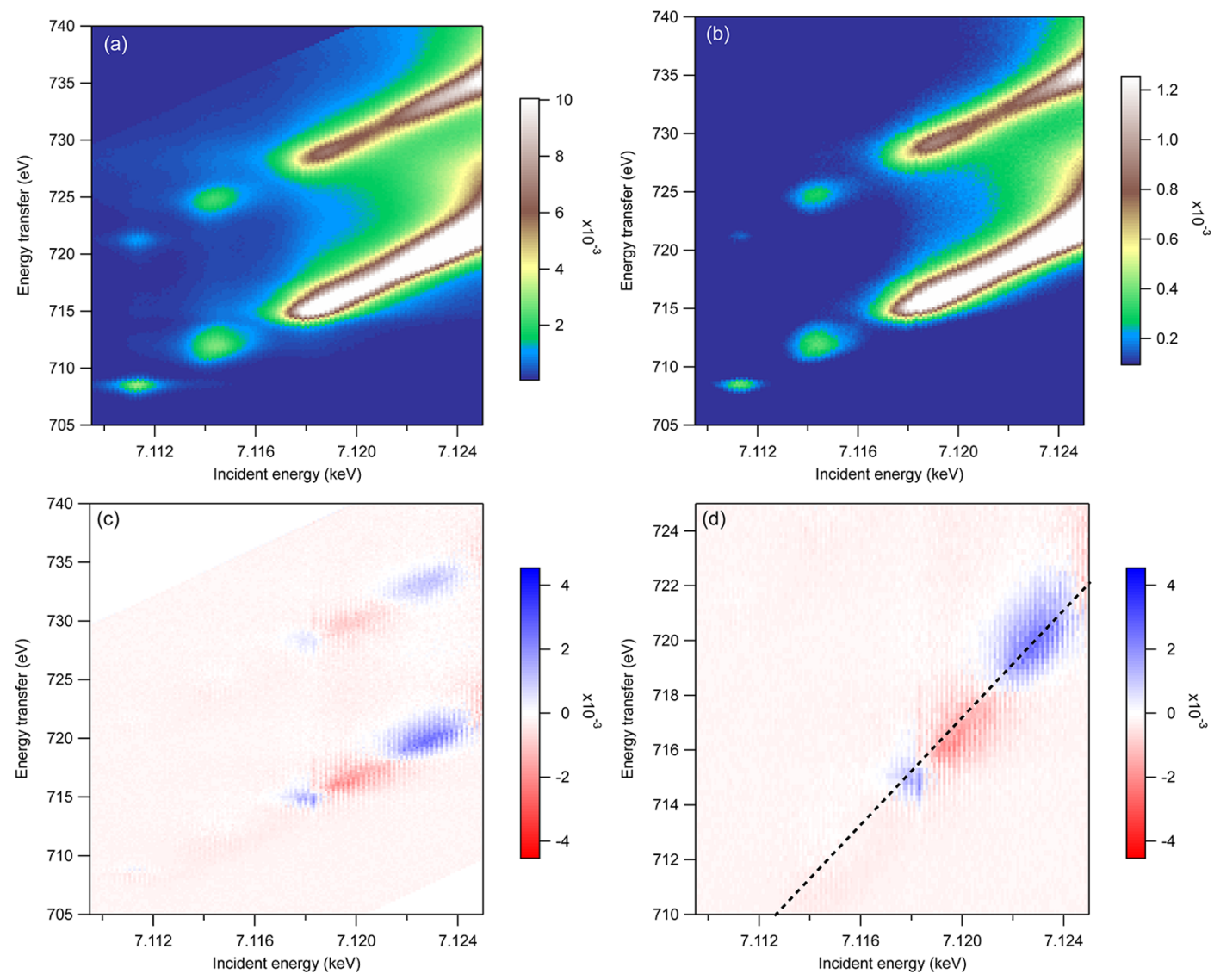

Figure 3. RIXS planes of $\left[\mathrm{Fe}(\mathrm{CN})_{6}\right]^{3-}$ in water (a) and ethylene glycol $(\mathrm{b})$. The difference spectrum $\left[\mathrm{Fe}(\mathrm{CN})_{6}\right]^{3-}($ water $)-\left[\mathrm{Fe}(\mathrm{CN})_{6}\right]^{3-}$ (ethylene glycol), after the latter has been scaled by a factor of 8 to account for the different concentrations, is shown in (c). (d) A zoom of the difference spectrum on the $\mathrm{K} \alpha_{1}$ emission line. CIE is the constant incident energy axis, and CET is the constant energy transfer axis. CEE is the constant emission energy axis.

XES shown in Figure S1a (SI), for which a similar effect is observed. This shift, derived by taking the difference of the redshifted spectrum in water minus itself, is $<0.1 \mathrm{eV}$, which, although small, corresponds to a lowering of the $2 p_{1 / 2}$ and $2 p_{3 / 2}$ levels and is consistent with a small loss of charge density on the iron when the complex is dissolved in water.

Using the CEE axis of the RIXS planes, we extract the $\mathrm{Fe} \mathrm{K} \alpha$ HERFD spectra for $\left[\mathrm{Fe}(\mathrm{CN})_{6}\right]^{4-}$ in both solvents. These are shown in Figure 2a. For both solvents, the above ionization resonances are in agreement with previously reported spectra, ${ }^{15-17}$ indicating that the solvent does not alter the geometric structure of the solute or, most probably, that their spectra are not sensitive to it. Indeed, previous analysis of these resonances ${ }^{15,17,32}$ has demonstrated that they are dominated by multiple scattering (MS) pathways along the linear $\mathrm{Fe}-\mathrm{C}-\mathrm{N}$ 

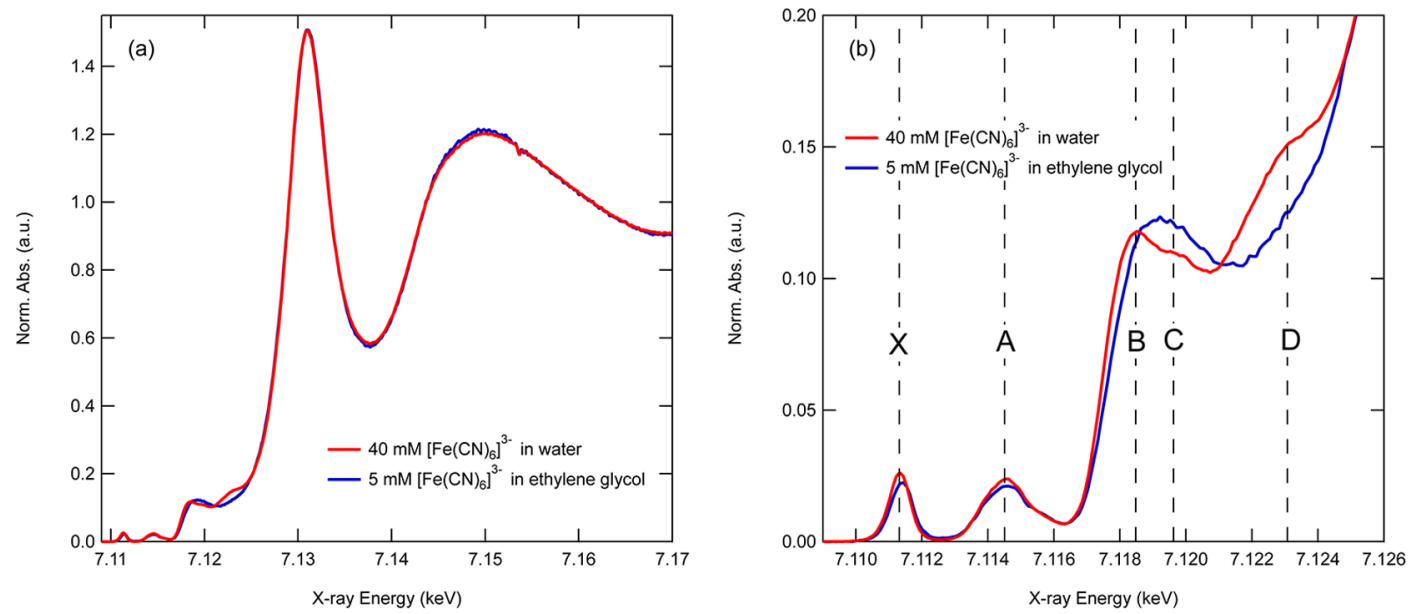

Figure 4. (a) The $\mathrm{K} \alpha$ XANES spectra of $\left[\mathrm{Fe}(\mathrm{CN})_{6}\right]^{3-}$ dissolved in water (red) and ethylene glycol (blue). (b) A zoom of the pre-edge region of the two spectra.
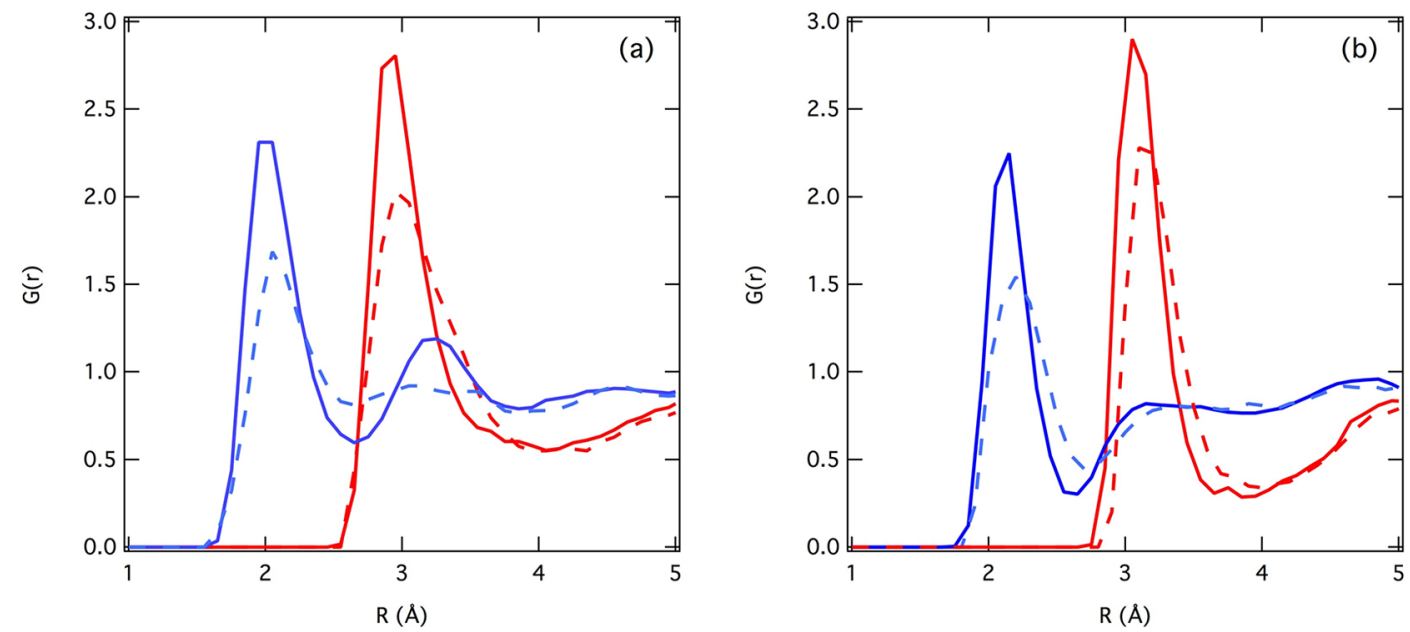

Figure 5. $\mathrm{N}-\mathrm{O}$ (red) and $\mathrm{N}-\mathrm{H}$ (blue) $\mathrm{RDFs}$ for $\left[\mathrm{Fe}(\mathrm{CN})_{6}\right]^{4-}$ (solid line) and $\left[\mathrm{Fe}(\mathrm{CN})_{6}\right]^{3-}$ (dotted line) in water (a) and ethylene glycol (b) extracted from a $60 \mathrm{ps} \mathrm{QM} / \mathrm{MM} \mathrm{MD}$ trajectory. The computational details are described in the SI.

bonds, reporting $\mathrm{Fe}-\mathrm{C}$ distances of $1.90 \AA$ and $\mathrm{C}-\mathrm{N}$ distances of $1.19 \AA$.

Figure $2 \mathrm{~b}$ shows a zoom of the pre-edge region of the $\mathrm{Fe} \mathrm{K} \alpha$ HERFD spectra. These high-resolution spectra, recorded for the first time in solution, reveal a number of discrete transitions (labeled A-D), which are largely obscured in previous total fluorescence yield measurements. ${ }^{25}$ Importantly, they are solvent-dependent. In water, the B feature is slightly shifted toward lower energies. However, the most pronounced difference occurs just before the rising edge, for which the $\mathrm{D}$ feature is observed in water but is significantly weaker or absent in ethylene glycol.

Ferric Hexacyanide. Figure $3 \mathrm{a}$ and $\mathrm{b}$ shows the K $\alpha$ RIXS plane of $\left[\mathrm{Fe}(\mathrm{CN})_{6}\right]^{3-}$ dissolved in water and ethylene glycol, respectively. In comparison to $\left[\mathrm{Fe}(\mathrm{CN})_{6}\right]^{4-}$, we observe a $\sim 1$ $\mathrm{eV}$ oxidation shift of the absorption edge $\left(\mathrm{Fe}^{2+} \rightarrow \mathrm{Fe}^{3+}\right)$ and the appearance of a new pre-edge feature at $7.110 \mathrm{keV}$, arising from transitions into $\mathrm{Fe} 3 \mathrm{~d}\left(\mathrm{t}_{2 \mathrm{~g}}\right)$ orbitals owing to the $\mathrm{d}^{5}$ electron configuration of $\mathrm{Fe}^{3+}$.

The difference between the two spectra is shown in Figure $3 c$. As for ferrous hexacyanide, the largest changes occur at higher incident energies just before the rising edge. However, these differences are noticeably smaller than that in the former case, which indicates a weaker solute-solvent interaction as expected for a lower charge anion. In addition, we observe no apparent shift in the emission energies for the two solvents, unlike for $\left[\mathrm{Fe}(\mathrm{CN})_{6}\right]^{4-}$, meaning that the differences correspond to a shift of the spectral weights along the CEE axis. The nonresonant $\mathrm{K} \alpha \mathrm{XES}$ shown in Figure S1b (SI) does reveal that a small shift is present; however, it is a factor of 2 smaller than that in $\left[\mathrm{Fe}(\mathrm{CN})_{6}\right]^{4-}$.

Figure $4 \mathrm{a}$ shows the $\mathrm{Fe} \mathrm{K} \alpha \mathrm{HERFD}$ spectrum of $[\mathrm{Fe}-$ $\left.(\mathrm{CN})_{6}\right]^{3-}$. For the ferric complex, previous analysis ${ }^{15,17}$ observed a small $(0.03 \AA)$ expansion of the $\mathrm{Fe}-\mathrm{C}$ distance in comparison to $\left[\mathrm{Fe}(\mathrm{CN})_{6}\right]^{4-}$, while the $\mathrm{C}-\mathrm{N}$ distance remained constant. Importantly, the agreement of the MS features in the XANES spectra in the two solvents again implies that the spectra are not sensitive to the solvent or that the solvent does not influence the molecular structure.

A zoom into the pre-edge region is shown in Figure $4 b$, and the main features are labeled $\mathrm{X}$ and $\mathrm{A}-\mathrm{D}$. The new pre-edge feature $(\mathrm{X})$ is, as previously described, due to transitions into Fe $3 d\left(t_{2 g}\right)$ orbitals owing to the $d^{5}$ electron configuration of $\mathrm{Fe}^{3+}$. The A feature, as for $\left[\mathrm{Fe}(\mathrm{CN})_{6}\right]^{4-}$, is due to $1 \mathrm{~s} \rightarrow \mathrm{Fe}$ $3 \mathrm{~d}\left(\mathrm{e}_{\mathrm{g}}\right)$ transitions. The $\mathrm{B}-\mathrm{D}$ transitions are also similar to those observed for $\left[\mathrm{Fe}(\mathrm{CN})_{6}\right]^{4-}$, with their corresponding 

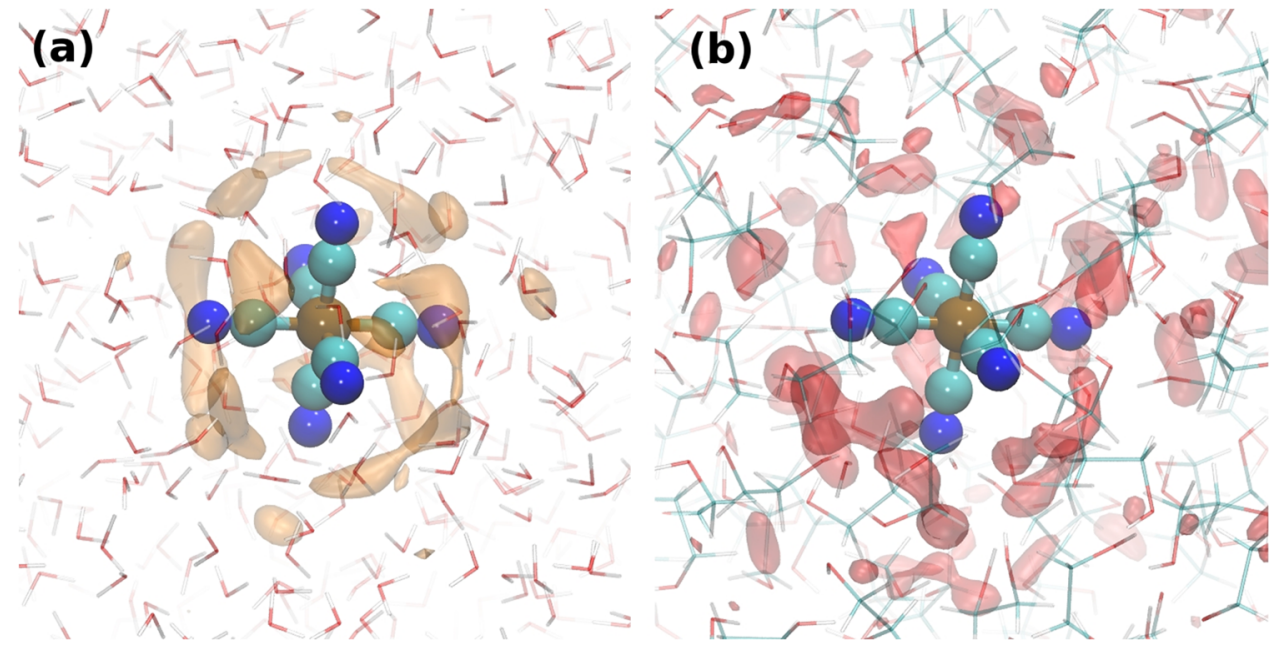

Figure 6. Angular solvent density of water (a) and ethylene glycol (b) around $\left[\mathrm{Fe}(\mathrm{CN})_{6}\right]^{4-}$. These density plots, shown with the same isovalue, are generated using the Situs program. ${ }^{35}$ Note that the density is the nuclear density and not the electronic density.

solvent effects also observed. The one difference is that, although still visible in water, the $\mathrm{C}$ transition is much weaker for $\left[\mathrm{Fe}(\mathrm{CN})_{6}\right]^{3-}$ in comparison to that for $\left[\mathrm{Fe}(\mathrm{CN})_{6}\right]^{4-}$.

MD Simulations. To rationalize the role of the solvent in the X-ray spectra of the two complexes, we have performed $\mathrm{QM} / \mathrm{MM} \mathrm{MD}$ simulations (described in the SI) for both complexes in either water or ethylene glycol. The $\mathrm{N}-\mathrm{O}$ and $\mathrm{N}-\mathrm{H}$ radial distribution functions (RDFs) extracted from a 60 ps trajectory for each simulation are shown in Figure 5. We observe, due to the favorable electrostatic interaction with the $\mathrm{CN}^{-}$ligands, that the hydrogens of both the water and ethylene glycol molecules are at shorter distances than the oxygens, that is, the protons point toward the complex, similar to the case of iodide in water. ${ }^{33}$

For $\left[\mathrm{Fe}(\mathrm{CN})_{6}\right]^{4-}$, on average, the water molecules are slightly closer to the $\mathrm{N}$ atoms than ethylene glycol, with the first solvation shell of oxygens occurring just under $3.0 \AA$, compared to just over $3 \AA$ for ethylene glycol. For $\left[\mathrm{Fe}(\mathrm{CN})_{6}\right]^{3-}$, the RDFs exhibit a similar structure to those of $\left[\mathrm{Fe}(\mathrm{CN})_{6}\right]^{4-}$, but in both cases, the first solvation shells are less distinct and at slightly larger distances. This change reflects the smaller charge of the complex and, therefore, a reduction in the electrostatic interaction between the solvent and the $\mathrm{CN}^{-}$ligands. This is consistent with recent 2D IR measurements by $\mathrm{Yu}$ et al., ${ }^{34}$ which concluded that the solvent shell of water around $\left[\mathrm{Fe}(\mathrm{CN})_{6}\right]^{4-}$ is more strongly bound than that in $\left[\mathrm{Fe}(\mathrm{CN})_{6}\right]^{3-}$.

Given the solvent effect on the pre-edge transitions observed in the previous sections, we expect the structure of the first solvation sphere around the complex and the hydrogen bonds present to be important. The first solvation shell structures $(R$ $<4.0 \AA$ ) are highlighted in Figure 6, which plots the solvent density around $\left[\mathrm{Fe}(\mathrm{CN})_{6}\right]^{4-}$ in both water (a) and ethylene glycol (b). For water, the solvent shell is organized and isotropic around the complex, owing to the stronger hydrogen bonding. This compact and structured distribution of the solvent close to the complex reflects a strong solute-solvent interaction, while, in contrast, the solvent shell of ethylene glycol is more unstructured in the close vicinity of the solute due to a slightly weaker interaction and a larger solvent viscosity. Indeed, the average number of hydrogen bonds (defined whenever the donor and acceptor atoms are $<3.0 \AA$ apart and the $\mathrm{D}-\mathrm{H}-\mathrm{A}$ angle is $<20^{\circ}$ ) for $R<4.0 \AA$ around $\left[\mathrm{Fe}(\mathrm{CN})_{6}\right]^{4-}$ is 12 for water and 8 for ethylene glycol.

\section{DISCUSSION}

The results presented in the previous sections demonstrate that (i) the above ionization features of the HERFD spectra are not sensitive to the structure of the solvent. This is likely due to the fact that the $\mathrm{O}$ atoms of the solvent shell molecules are too far from the $\mathrm{Fe}$ atom, and that the signal is dominated by the stronger backscattering contributions of the linear $\mathrm{CN}^{-}$ligands. (ii) A distinct solvent effect on the pre-edges of the K $\alpha$ RIXS is observed. This corresponds to a shifting of spectral weights along the $\mathrm{CEE}$ axis for transitions below the rising edge. In addition, for $\left[\mathrm{Fe}(\mathrm{CN})_{6}\right]^{4-}$, there is a shift along the energy transfer axis. This indicates a stabilization of the $2 \mathrm{p}_{1 / 2}$ and $2 \mathrm{p}_{3 / 2}$ levels, which is confirmed by the K $\alpha$ XES spectra. These results point to a clear solvent effect on the electronic structure of the hexacyanide anions, which is larger for $\left[\mathrm{Fe}(\mathrm{CN})_{6}\right]^{4-}$ than for $\left[\mathrm{Fe}(\mathrm{CN})_{6}\right]^{3-}$. In the following section, we use these results, in conjunction with the MD simulations to discuss the X-ray spectra and, in particular, the influence of the solvent.

In $\left[\mathrm{Fe}(\mathrm{CN})_{6}\right]^{4-}$, the first resonance $(\mathrm{A})$ corresponds to transitions into the $\mathrm{Fe} 3 \mathrm{~d}\left(\mathrm{e}_{\mathrm{g}}\right)$ molecular orbitals, ${ }^{31}$ and consequently, this quadrupole transition $(1 s-3 d)$ is weak. It is also largely independent of the solvent, except for a small enhancement of the transition strength of the high-energy side at $\sim 7.115 \mathrm{keV}$ in water. The energy difference between this enhancement and the peak of the A feature is consistent with the energy gap between the $\mathrm{d}-\mathrm{d}$ transitions and the charge transfer to solvent (CTTS) states in the UV/vis absorption spectrum (Figure S2, SI). ${ }^{23,36-40}$ Correspondingly, we assign this to the CTTS states.

The spectral region associated with features B-D is usually assigned to edge transitions. Our present spectra exhibit a similar spectral profile to those of other transition-metal cyanides; however, despite numerous studies, their exact assignment remains uncertain..$^{17,31,42}$ The first transition (B) occurs $\sim 3 \mathrm{eV}$ higher in energy than the $1 \mathrm{~s} \rightarrow 3 \mathrm{e}_{\mathrm{g}}$ transition. This energy gap is consistent with the excitation energy of the strong MLCT absorption in the UV/vis spectrum. ${ }^{25}$ This state has $\mathrm{T}_{1 \mathrm{u}}$ symmetry and, owing to substantial $4 \mathrm{p}+\pi^{*}$ mixing, it would be expected to be significantly stronger than the A feature, as observed. This assignment is also consistent with the assignment from the valence photoemission spectra of Seidel et al. ${ }^{41}$ Besides this, Lundberg et al. ${ }^{18}$ recently used multiplet 
simulations to show that two other MLCT transitions of $3 \mathrm{~d}+\pi$ and $3 \mathrm{~d}+\sigma^{*}$ character also contribute to the $\mathrm{B}$ feature. However, as pointed out by them, these quadrupole transitions are relatively weak in comparison to the transition to the $\mathrm{T}_{1 \mathrm{u}}$ state. The $\mathrm{C}$ feature has not been observed in any of the previous studies of transition-metal cyanides, ${ }^{17,31,42}$ which have either been performed using solid samples or have been limited by core-hole lifetime broadening effects. Using the molecular orbital diagram presented in Figure S3 (SI) and ref 31, we tentatively assign it to a higher-lying $\mathrm{t}_{1 \mathrm{u}}$ molecular orbital, which has a predominately ligand $\sigma^{*}$ character but mixes with the $\mathrm{Fe}$ 4 p orbitals. ${ }^{43}$

Finally, the D feature occurs $4 \mathrm{eV}$ higher in energy than $\mathrm{B}$ and exhibits the largest solvent effect. Interestingly, a comparably strong environment effect in this region of the spectrum was reported by Hayakawa et al. ${ }^{17}$ They recorded the iron K-edge of both crystalline and aqueous $\left[\mathrm{Fe}(\mathrm{CN})_{6}\right]^{4-}$ and showed an enhancement of a factor of 1.5 for the crystal sample in this region of the spectrum. They suggested that this could reflect long-range order effects present in the crystal, which are obviously absent for the hydrated complex. Here, we propose a somewhat similar explanation, but in this case, the longer-range order refers to the structure of the first solvation shell. As demonstrated by the MD simulations of the previous section, the closest solvent shell in the case of water is more structured than that in ethylene glycol. This gives rise to additional core transitions due to the interaction of diffuse electrons (due to the highly excited state), most likely those in $\mathrm{T}_{1 \mathrm{u}}$ orbitals with predominantly ligand character, ${ }^{42}$ with the solvent network. These can be seen as analogous to CTTS states. For a less ordered solvent environment, as found in ethylene glycol, these transitions would be expected to be quenched, which may explain the loss of intensity associated with the $\mathrm{D}$ feature in ethylene glycol.

By comparing the spectra in Figure $2 b$ for water and ethylene glycol, the differences between the $\mathrm{B}$ and $\mathrm{C}$ features reflect the solvent-induced changes to the electronic structure of the complexes. In water, the $\mathrm{B}$ feature shifts to lower energy, which points to either the $4 p+\pi^{*}, 3 d+\pi$, and/or $3 d+\sigma^{*}$ orbitals being stabilized, although as the quadrupole components for the latter are weak, it is most likely to be the former $\left(4 p+\pi^{*}\right)$. Indeed, while small, this effect is confirmed by a shift of a similar magnitude observed in the UV-vis absorption spectra shown in Figure S2 (SI).

Given that the MD simulations have shown a highly structured solvent shell around $\left[\mathrm{Fe}(\mathrm{CN})_{6}\right]^{4-}$, we expect that the hydrogen bonding between the complex and the nearest solvent molecules plays a significant role in this, and as previously shown, the number of hydrogen bonds to the complex is slightly greater for water than that for ethylene glycol. In support of this, a study on the nitroprusside $\left(\left[\mathrm{Fe}(\mathrm{CN})_{5} \mathrm{NO}\right]^{2-}\right)$ complex reported that the energy of the MLCT band was linearly dependent on the solvent acceptor number (i.e., the quantitative measure of its Lewis basicity). The authors concluded that a strong interaction between the solvent and the cyanides causes electron withdrawal from the $\pi$ electron density of the cyanides. ${ }^{44,45}$ This withdrawal of $\pi$ electron density from the $\mathrm{CN}^{-}$helps stabilize the negative charge on the ligands and therefore the molecular orbitals, causing a shift of the B feature to lower energies. Importantly, this effect is somewhat compensated for by an increase in $\pi$ backbonding. This increase in the $\pi$-backbonding reduces the charge on the Fe and causes the blue shift in the emission spectrum seen in both the K $\alpha$ RIXS and XES spectra. In addition, for such cases, an analogous change in $\sigma$-donation it could be expected. Such a decrease will destabilize the higherlying $\mathrm{t}_{\mathrm{lu}}\left(4 \mathrm{p}+\sigma^{*}\right)$ molecular orbital assigned to the $\mathrm{C}$ feature and, as observed, shift it to slightly higher energies. Importantly, as this is a higher-lying valence orbital, this interaction will not affect the bonding in the ground state.

The $\mathrm{d}^{5}$ configuration of iron in ferricyanide implies that, besides the $\sim 1 \mathrm{eV}$ shift associated with the change in oxidation state, its spectra are likely to contain a stronger contribution from multiplet effects. Indeed, Westre et al. recorded the Fe Kedge of $\left[\mathrm{Fe}(\mathrm{CN})_{6}\right]^{3-}$ and observed that the three pre-edge transitions at $7.111,7.113 .3$, and $7.114 .5 \mathrm{keV},{ }^{31}$ correspond to $\mathrm{X}, \mathrm{A}$, and the shoulder on $\mathrm{A}$ in our present spectrum. The new pre-edge feature $(\mathrm{X})$ at $7.110 \mathrm{keV}$ arises from transitions into $2 t_{2 g}$ orbitals, while A remains the same as that for ferrous cyanide. The shoulder on the high-energy side of the A feature $(\sim 7.115 \mathrm{keV})$ arises from a weak multiplet effect. ${ }^{31}$ Comparing the spectra for $\left[\mathrm{Fe}(\mathrm{CN})_{6}\right]^{3-}$ in water or ethylene glycol, we observe the same trends for the $\mathrm{B}, \mathrm{C}$, and $\mathrm{D}$ features that are observed for $\left[\mathrm{Fe}(\mathrm{CN})_{6}\right]^{4-}$. However, in this case, the effect is weaker, and the features are less pronounced due to the smaller charge of the anion, which reduces the solvent-solute interaction strength.

\section{CONCLUSION}

The role of a solvent in influencing the electronic structure of a solute can be of critical importance to many chemical and biological phenomena as these changes can have a profound effect on the rate and/or selectivity of reactions. Using $\mathrm{K} \alpha$ RIXS and XES spectroscopy, supported by MD simulations, we have shown that both $\left[\mathrm{Fe}(\mathrm{CN})_{6}\right]^{4-}$ and $\left[\mathrm{Fe}(\mathrm{CN})_{6}\right]^{3-}$ exhibit a significant solvent effect on the electronic structure. Its origin is the high charge of the complexes, which leads to a strong solvent-solute interaction. In particular, the hydrogen bonds between the solute and solvent withdraw electron density from the $\mathrm{CN}^{-}$, helping to stabilize the complex. This loss of charge on the ligands is compensated for by an increase of $\pi$ backbonding, as demonstrated by the blue-shifted emission for the complex in water, especially for $\left[\mathrm{Fe}(\mathrm{CN})_{6}\right]^{4-}$.

As a final note, the conclusions drawn from this work are largely qualitative and/or based upon previous experiments. Fully addressing these conclusions computationally is desirable but represents a significant challenge. In order to accurately capture the $\pi$-backbonding and $\sigma$-donation effects on the corehole spectra using an ab initio method, a high-level correlated wave function method approach is required. While such methodologies have been implemented for ${ }^{46}$ the strong interaction with the solvents arising from the diffuse electronic structure implies that an explicit description of the solvent molecules is required, making this very computationally challenging.

\section{ASSOCIATED CONTENT}

\section{Supporting Information}

Fe $\mathrm{K} \alpha$ emission spectra, absorption spectra, and a schematic molecular orbital diagram, along with details of the experimental materials and procedures. This material is available free of charge via the Internet at http://pubs.acs.org.

\section{AUTHOR INFORMATION}

\section{Corresponding Author}

*E-mail: majed.chergui@epfl.ch. 


\section{Notes}

The authors declare no competing financial interest.

\section{ACKNOWLEDGMENTS}

This work was supported by the Swiss NSF through the NCCR MUST 'Molecular ultrafast science and technology' and Contracts 200020-135502 and 200021-144517, as well as by the COST action XLIC (CM1204)

\section{REFERENCES}

(1) Bertini, I.; HB, G.; Lippard, S.; Valentine, J. Bioinorganic Chemistry; University Science Books: Herndon, VA, 1994.

(2) Calderazzo, F. et al. In Metal Catalysis in Industrial Organic Processes; Chiusoli, G. P., Maitlis, P. M., Eds.; The Royal Society of Chemistry: Cambridge, U.K., 2007; pp 001-290.

(3) Szacilowski, K.; Stasicka, Z. Molecular Switches Based on Cyanoferrate Complexes. Coord. Chem. Rev. 2002, 229, 17-26.

(4) De Angelis, F.; Tilocca, A.; Selloni, A. Time-Dependent DFT Study of $\left[\mathrm{Fe}(\mathrm{CN})_{6}\right]^{4-}$ Sensitization of $\mathrm{TiO}_{2}$ Nanoparticles. J. Am. Chem. Soc. 2004, 126, 15024-15025.

(5) Lima, F. A.; Penfold, T. J.; van der Veen, R.; Reinhard, M.; Abela, R.; Tavernelli, I.; Rothlisberger, U.; Benfatto, M.; Milne, C. J.; Chergui, M. Probing the Electronic and Geometric Structure of Ferric and Ferrous Myoglobins in Physiological Solutions by Fe K-Edge Absorption Spectroscopy. Phys. Chem. Chem. Phys. 2014, 16, 16171631.

(6) El Nahhas, A.; et al. X-ray Absorption Spectroscopy of Ground and Excited Rhenium-Carbonyl-Diimine Complexes: Evidence for a Two-Center Electron Transfer. J. Phys. Chem. A 2013, 117, 361-369.

(7) Chatt, J.; Duncanson, L. A. 586. Olefin Co-ordination Compounds. Part III. Infra-Red Spectra and Structure: Attempted Preparation of Acetylene Complexes. J. Chem. Soc. 1953, 2939-2947.

(8) Frenking, G. Understanding the Nature of the Bonding in Transition Metal Complexes: From Dewar's Molecular Orbital Model to an Energy Partitioning Analysis of the Metal-Ligand Bond. J. Organomet. Chem. 2001, 635, 9-23.

(9) Jean, Y. Molecular Orbitals of Transition Metal Complexes; Oxford University Press: New York, 2005.

(10) Milne, C. J.; Penfold, T. J.; Chergui, M. Recent Experimental and Theoretical Developments in Time-Resolved X-ray Spectroscopies. Coord. Chem. Rev. 2014, DOI: 10.1016/j.ccr.2014.02.013.

(11) De Groot, F.; Kotani, A. Core Level Spectroscopy of Solids; CRC Press: Boca Raton, FL, 2008.

(12) Hocking, R.; Wasinger, E.; de Groot, F.; Hodgson, K.; Hedman, B.; Solomon, E. Fe L-Edge XAS Studies of $\mathrm{K}_{4}\left[\mathrm{Fe}(\mathrm{CN})_{6}\right]$ and $\mathrm{K} 3[\mathrm{Fe}(\mathrm{CN}) 6]$ : A Direct Probe of Back-Bonding. J. Am. Chem. Soc. 2006, 128, 10442-10451.

(13) Vinogradov, A. S.; Preobrajenski, A. B.; Knop-Gericke, A.; Molodtsov, S. L.; Krasnikov, S. A.; Nekipelov, S. V.; Szargan, R.; Hävecker, M.; Schlögl, R. Observation of Back-Donation in 3d Metal Cyanide Complexes Through NK Absorption Spectra. J. Electron Spectrosc. Relat. Phenom. 2001, 114, 813-818.

(14) Vinogradov, A. S.; Preobrajenski, A. B.; Krasnikov, S. A.; Chassé, T.; Szargan, R.; Knop-Gericke, A.; Schlögl, R.; Bressler, P. X-ray Absorption Evidence for the Back-Donation in Iron Cyanide Complexes. Surf. Rev. Lett. 2002, 9, 359-364.

(15) Bianconi, A.; Dell'Ariccia, M.; Durham, P. J.; Pendry, J. B. Multiple-Scattering Resonances and Structural Effects in the X-rayAbsorption Near-Edge Spectra of Fe II and Fe III Hexacyanide Complexes. Phys. Rev. B 1982, 26, 6502.

(16) Obashi, M. X-Ray Fe K Absorption Edges of $\left[\mathrm{Fe}(\mathrm{CN})_{6}\right]^{4-}$ and $\left[\mathrm{Fe}(\mathrm{CN})_{6}\right]^{3-}$. Jpn. J. Appl. Phys. 1978, 17, 563-566.

(17) Hayakawa, K.; Hatada, K.; D’Angelo, P.; Della-Longa, S.; Natoli, C. R.; Benfatto, M. Full Quantitative Multiple-Scattering Analysis of Xray Absorption Spectra: Application to Potassium Hexacyanoferrat(II) and -(III) Complexes. J. Am. Chem. Soc. 2004, 126, 15618-15623.

(18) Lundberg, M.; Kroll, T.; DeBeer, S.; Bergmann, U.; Wilson, S. A.; Glatzel, P.; Nordlund, D.; Hedman, B.; Hodgson, K. O.; Solomon,
E. I. Metal-Ligand Covalency of Iron Complexes from HighResolution Resonant Inelastic X-ray Scattering. J. Am. Chem. Soc. 2013, 135, 17121-17134.

(19) Weaver, M. Dynamical Solvent Effects on Activated ElectronTransfer Reactions: Principles, Pitfalls, and Progress. Chem. Rev. 1992, 92, 463-480.

(20) Chen, P.; Meyer, T. J. Medium Effects on Charge Transfer in Metal Complexes. Chem. Rev. 1998, 98, 1439-1478.

(21) Bühl, M.; Mauschick, F. T. Thermal and Solvent Effects on ${ }^{57} \mathrm{Fe}$ NMR Chemical Shifts. Phys. Chem. Chem. Phys. 2002, 4, 5508-5514.

(22) Aziz, E. F.; Rittmann-Frank, M. H.; Lange, K. M.; Bonhommeau, S.; Chergui, M. Charge Transfer to Solvent Identified Using Dark Channel Fluorescence-Yield L-Edge Spectroscopy. Nat. Chem. 2010, 2, 853-857.

(23) Shirom, M.; Stein, G. Excited State Chemistry of the Ferrocyanide Ion in Aqueous Solution. I. Formation of the Hydrated Electron. J. Chem. Phys. 1971, 55, 3372.

(24) Shirom, M.; Stein, G. Excited State Chemistry of the Ferrocyanide Ion in Aqueous Solution. II. Photoaquation. J. Chem. Phys. 1971, 55, 3379.

(25) Reinhard, M.; Penfold, T.; Lima, F.; Rittmann, J.; RittmannFrank, M.; Abela, R.; Taverenelli, I.; Rothlisberger, U.; Milne, C. J.; Chergui, M. Photooxidation and Photoaquation of Iron Hexacyanide in Aqueous Solutions: A Picosecond X-ray Absorption Study. Struct. Dyn. 2014, 1, 024901.

(26) Glatzel, P.; Bergmann, U. High Resolution 1s Core Hole X-ray Spectroscopy in 3d Transition Metal Complexes Electronic and Structural Information. Coord. Chem. Rev. 2005, 249, 65-95.

(27) Glatzel, P.; Sikora, M.; Smolentsev, G.; Fernandez-Garcia, M. Hard X-ray Photon-In Photon-Out Spectroscopy. Catal. Today 2009, $145,294-299$.

(28) Rothlisberger, U.; Carloni, P. Drug-Target Binding Investigated by Quantum Mechanical/Molecular Mechanical (QM/MM) Methods. Lect. Notes Phys. 2006, 704, 437-466.

(29) Laio, A.; VandeVondele, J.; Rothlisberger, U. D-RESP: Dynamically Generated Electrostatic Potential Derived Charges from Quantum Mechanics/Molecular Mechanics Simulations. J. Phys. Chem. B 2002, 106, 7300-7307.

(30) Laio, A.; VandeVondele, J.; Rothlisberger, U. A Hamiltonian Electrostatic Coupling Scheme for Hybrid Car-Parrinello Molecular Dynamics Simulations. J. Chem. Phys. 2002, 116, 6941-6947.

(31) Westre, T. E.; Kennepohl, P.; DeWitt, J. G.; Hedman, B.; Hodgson, K. O.; Solomon, E. I. A Multiplet Analysis of Fe K-Edge 1s3d Pre-Edge Features of Iron Complexes. J. Am. Chem. Soc. 1997, 119, $6297-6314$

(32) Penfold, T. J.; Tavernelli, I.; Milne, C. J.; Reinhard, M.; Nahhas, A. E.; Abela, R.; Rothlisberger, U.; Chergui, M. A Wavelet Analysis for the X-ray Absorption Spectra of Molecules. J. Chem. Phys. 2013, 138, 014104.

(33) Penfold, T. J.; Tavernelli, I.; Doemer, M.; Abela, R.; Rothlisberger, U.; Chergui, M. Solvent Rearrangements during the Transition from Hydrophilic to Hydrophobic Solvation. Chem. Phys. 2013, 410, 25-30.

(34) Yu, P.; Yang, F.; Zhao, J.; Wang, J. Hydration Dynamics of Cyanoferrate Anions Examined by Ultrafast Infrared Spectroscopy. J. Phys. Chem. B 2014, 118, 3104-3114.

(35) Wriggers, W.; Milligan, R. A.; McCammon, J. A. Situs: A Package for Docking Crystal Structures into Low Resolution Maps From Electron Microscopy. J. Struct. Biol. 1999, 125, 185-195.

(36) Rentzepis, P.; Jones, R.; Jortner, J. Relaxation of Excess Electrons in a Polar Solvent. Chem. Phys. Lett. 1972, 15, 480-482.

(37) Mialocq, J.-C.; Sutton, J.; Goujon, P. Picosecond Study of Electron Ejection in Aqueous Phenol and Phenolate Solutions. J. Chem. Phys. 1980, 72, 6338-6345.

(38) Pommeret, S.; Naskrecki, R.; van der Meulen, P.; Ménard, M.; Vigneron, G.; Gustavsson, T. Ultrafast Events in the Electron Photodetachment from the Hexacyanoferrate(II) Complex in Solution. Chem. Phys. Lett. 1998, 288, 833-840. 
(39) Anderson, N. A.; Hang, K.; Asbury, J. B.; Lian, T. Ultrafast MidIR Detection of the Direct Precursor to the Presolvated Electron Following Electron Ejection from Ferrocyanide. Chem. Phys. Lett. 2000, 329, 386-392.

(40) Lenchenkov, V.; Kloepfer, J.; Vilchiz, V.; Bradforth, S. E. Electron Photodetachment from $\left[\mathrm{Fe}(\mathrm{CN})_{6}\right]^{4-}$ : Photoelectron Relaxation and Geminate Recombination. Chem. Phys. Lett. 2001, 342, 277286.

(41) Seidel, R.; Thurmer, S.; Moens, J.; Geerlings, P.; Blumberger, J.; Winter, B. Valence Photoemission Spectra of Aqueous $\mathrm{Fe}^{2+} /^{3+}$ and $\left[\mathrm{Fe}(\mathrm{CN})_{6}\right]^{4-/ 3-}$ and Their Interpretation by DFT Calculations. J. Phys. Chem. B 2011, 115, 11671.

(42) Meyer, D. A.; Zhang, X.; Bergmann, U.; Gaffney, K. J. Characterization of Charge Transfer Excitations in Hexacyanomanganate(III) with Mn K-Edge Resonant Inelastic X-ray Scattering. J. Chem. Phys. 2010, 132, 134502.

(43) Alexander, J. J.; Gray, H. B. Molecular Orbital Theory for Metal Complexes: Ferrocyanide and Cobalticyanide Ions. Coord. Chem. Rev. 1967, 2, 15-28.

(44) Estrin, D. A.; Baraldo, L. M.; Slep, L. D.; Barja, B. C.; Olabe, J. A.; Paglieri, L.; Corongiu, G. Theoretical and Experimental Study of Medium Effects on the Structure and Spectroscopy of the [Fe$\left.(\mathrm{CN})_{5} \mathrm{NO}\right]^{2-}$ Ion. Inorg. Chem. 1996, 35, 3897-3903.

(45) Estrin, D. A.; Hamra, O. Y.; Paglieri, L.; Slep, L. D.; Olabe, J. A. Structure and Bonding in Pentacyano (L) ferrate (II) and Pentacyano (L) ruthenate (II) Complexes (L = Pyridine, Pyrazine, and $\mathrm{N}$ Methylpyrazinium): A Density Functional Study. Inorg. Chem. 1996, 35, 6832-6837.

(46) Josefsson, I.; Kunnus, K.; Schreck, S.; Föhlisch, A.; de Groot, F.; Wernet, P.; Odelius, M. Ab Initio Calculations of X-ray Spectra: Atomic Multiplet and Molecular Orbital Effects in a Multiconfigurational SCF Approach to the L-Edge Spectra of Transition Metal Complexes. J. Phys. Chem. Lett. 2012, 3565-3570. 